\title{
“FÉMINISTAS"*: A RECONSTRUÇÃO DA VIVÊNCIA FEMININA NO ENQUADRAMENTO CRISTÃO BRASILEIRO
}

\author{
Maria Eduarda Antonino Vieira**
}

\section{RESUMO}

Essa artigo' busca compreender como as mulheres cristãs percebem a construção dos seus direitos, através do que as próprias mulheres religiosas dentro de coletivos, organizações e associações têm a dizer a respeito. Para isso, foram utilizados documentos de páginas oficiais e sites de grupos ativistas, associações e organizações de mulheres cristãs ou com projetos voltados para essa comunidade, entre os anos de 2012 e 2019. Foi empregada a Análise de Discurso, a qual percebe o discurso como prática social. As tendências gerais observadas em relação à formação discursiva das cristãs foram em oposição, por um lado, à comunidade de cristãos e às desigualdades de gênero perpetradas em nome de Deus e, por outro, à comunidade maior e suas atitudes discriminatórias para com a religião.

Palavras-Chaves: Religião, feminismo, movimentos sociais.

* O movimento Féministas reúne feministas jovens de todas as religiões e é organizado pelas Católicas pelo Direito de Decidir em parceria com a Koinonia Presença Ecumênica, duas organizações que foram objetos de análises do trabalho.

** Doutoranda em Ciências Sociais pela Universidade Federal de Pernambuco (UFPE). Mestra em Ciência Política pela Universidade Federal de Pernambuco (UFPE). Graduada em Relações Internacionais pela Faculdade Damas.

1 Este artigo é parte de uma pesquisa maior que está em desenvolvimento e busca compreender como as mulheres cristãs (de todas as vertentes), que atuam no Brasil através de grupos coletivos e associações, percebem e participam da construção dos seus direitos. A pesquisa possui três objetivos: 1) mapear os principais grupos, organizações e coletivos de mulheres religiosas cristã; 2) sistematizar sua mobilização, suas redes, os locais onde atuam, sua identidade e seus projetos; e 3) elencar as principais pautas do movimento de mulheres cristãs e perceber quais dessas pautas dialogam com o feminismo secular. Neste artigo, pela impossibilidade de abrangência, apresentaremos a participação dessas mulheres através da apresentação de alguns coletivos, por isso, as conclusões são relativas aos grupos analisados e não abarcam os vários outros coletivos que existem tanto no espaço virtual como no espaço social "real" que não foram objetos de análises. A pesquisa está sendo desenvolvida com o objetivo maior de oferecer algo incomum para um público que tem pouca compreensão das mulheres religiosas, mas fortes opiniões, tentando afastá-los da apresentação da religião e das mulheres como parte de um todo misógino e atrasado. 


\section{FÉMINISTAS: THE RECONSTRUCTION OF WOMEN'S EXPERIENCE IN THE BRAZILIAN CHRISTIAN FRAMEWORK}

\section{ABSTRACT}

This research is aimed at understanding how Christian women perceive the construction of their rights, through what themselves have to say about it. For this, documents were used from official pages and websites of activist groups, associations and organizations of Christian women or with projects aimed at this community, between the years 2012 and 2019. It was used the Discourse Analysis which perceives the speech as a social practice. The general trends observed regarding the discursive formation of Christians were in opposition, on the one hand, to the Christian community and the gender inequalities perpetrated in the name of God and, on the other, to the larger community and its discriminatory attitudes towards religion. Keywords: Religion, feminism, social movements.

\section{FÉMINISTAS: LA RECONSTRUCCIÓN DE LA EXPERIENCIA DE LAS MUJERES EN EL MARCO CRISTIANO BRASILEÑO}

\section{RESUMEN}

Esta investigación tiene como objetivo comprender cómo las mujeres cristianas perciben la construcción de sus derechos, a través de lo que las propias religiosas tienen que decir al respecto. Para ello, se utilizaron documentos de páginas oficiales y sitios web de grupos activistas, asociaciones y organizaciones de mujeres cristianas o con proyectos dirigidos a esta comunidad, entre los años 2012 y 2019. Se utilizó el Análisis del Discurso que percibe el discurso como una práctica social. Las tendencias generales observadas con respecto a la formación discursiva de las cristianas estaban en oposición, por un lado, a la comunidad cristiana y las desigualdades de género perpetradas en nombre de Dios y, por el otro, a la comunidad en general y sus actitudes discriminatorias hacia la religión.

Palabras clave: Religión, feminismo, movimientos sociales.

\section{INTRODUÇÃO}

O tópico mulher e religião pode ser facilmente inter-relacionado de maneira reducionista e preconceituosa pela sociedade secular. As mulheres religiosas podem ser observadas como submissas por conta 
de temas como aborto, contraceptivos, divórcio e vestimenta que são facilmente prejulgados pelos/as seculares. Dessa forma, através de um recorte de gênero, o artigo busca compreender: como as mulheres católicas e evangélicas dentro de coletivos e associações percebem e participam das construções dos seus direitos. De que forma as mulheres articulam suas vidas e seus desejos no enquadramento religioso? Como elas subvertem, apropriam e reinterpretam o discurso religioso? Como elas articulam o interesse individual com o interesse das igrejas? Existem instrumentos de luta que resultam, de alguma forma, na diminuição das discriminações de gênero no interior da Igreja? Dessa forma, afasta-se das perspectivas teóricas essencialistas que apontam todo enquadramento religioso como opressivo e toda mulher religiosa como passiva, e direciona a investigação para as formas de ação que transgridem, desconstroem e divergem ou demonstram que tais análises reducionistas precisam ser revistas ou complexificadas.

Dessa forma, as questões que vão atravessar esse artigo ${ }^{2}$ interrogam exatamente as construções teóricas em torno das relações de gênero e religião, através de uma perspectiva crítica. Afinal, é importante pensar gênero no contexto cristão brasileiro, mas sem ser através de uma lente preconceituosa e reducionista que já caracteriza a religião como patriarcal e que enquadra os cenários seculares como os únicos

Dado que este artigo tem como prioridade compreender como as mulheres católicas e evangélicas, dentro dos coletivos objetos de análise, percebem a construção dos seus direitos, primeiramente, é preciso deixar claro que o termo "mulheres cristã" tem sido usado durante o trabalho num sentido amplo, quando na verdade, ele deve ser compreendido pelas católicas e evangélicas ativistas que estão organizadas em espaços como os que serão analisados. 0 levantamento dos dados primários foi através da Internet como ferramenta-chave para a coleta, abarcando documentos escritos, fotografias e vídeos produzidos no contexto de um conjunto de espaços e plataformas pesquisadas. Nessa pesquisa, utilizou-se o Dedoose, uma plataforma online específica de métodos qualitativos e mistos de análise, ajudando no gerenciamento, integração e análises de textos, vídeos, áudios, imagens, planilhas e outros tipos de dados. Também utilizou-se da Análise do Discurso de linha francesa (AD), que segundo Rosalind Gill (2008), é o nome dado a uma variedade de diferentes enfoques no estudo de textos, desenvolvida a partir de diferentes tradições teóricas e diversos tratamentos em diferentes disciplinas. Os analistas de discurso veem todo discurso como prática social, preocupando-se em ir além do conteúdo, analisar a forma como se diz alguma coisa, quem está falando e para quem se fala, rejeitando a noção objetivista e instrumentalista de que a linguagem é simplesmente um meio neutro de refletir ou descrever o mundo (Rosalind GILL, 2008). 
propensos à emancipação feminina. Mais do que pensar se a religião é patriarcal ou não, se o cristianismo é a mais patriarcal de todas as crenças, se a mulher cristã é a mais oprimida, é importante ter em mente que existe, em todas as religiões, uma relação entre a fé e os/as indivíduos/ as que geram consequências particulares (Ann BRAUDE, 2004).

\section{MULHER, RELIGIÃO E SUBALTERNIDADE}

No Brasil, a religião, enquanto objeto de estudo sistemático, ocupou "um lugar marginal e de importância secundária" na academia (Rubem ALVES, 1978, p. 112). Tal resistência, que em certa dose ainda persiste, provavelmente deriva da herança do positivismo e sua aversão quase religiosa-fundamentalista ao tema (Pedro OLIVEIRA, 1998, p. 21). A religião é, antes de tudo, uma construção sociocultural. Portanto, discutir religião é discutir transformações sociais, relações de poder, de classe, de gênero, de raça/etnia; é adentrar num complexo sistema de trocas simbólicas, de jogos de interesse; é deparar-se com um sistema sociocultural constantemente redesenhado que permanentemente redesenha as sociedades (Antônio Flávio PIERUCCI, 1997, p. 99-117).

Nas Ciências Sociais, existe uma crescente produção cientifica sobre a religião, principalmente no Brasil, devido à grande visibilidade que grupos evangélicos vêm ganhando no campo político, além do expressivo crescimento numérico de fiéis (Joanildo BURITY; Maria das Dores C. MACHADO, 2014). Entretanto, poucos trabalhos têm tido a preocupação de fazer uma análise do religioso através do recorte de gênero (Crislaine TOLEDO-FRANCISCO, 2002). Os estudos da religião e gênero ainda se esforçam para sair da condição de outsiders na academia. Pesquisadores/as dessa temática sublinham que as produções brasileiras relativas às religiões não mencionam a temática de gênero, enquanto os balanços na área de estudos de gênero não contemplam a produção acadêmica no campo dos estudos da religião ${ }^{3}$.

Ao falarmos de estudos da religião e gênero no Brasil, vale salientar que as contribuições dos Cadernos Pagu, da Revista Estudos Feministas e da Revista Mandrágora, representam o importante esforço de diversos/as pesquisadores/as do fenômeno religioso, que, a partir de diferentes perspectivas, têm se proposto aprofundar as discussões em torno do assunto. Todavia, o estágio atual de pesquisas relacionadas aos temas mostra um número ainda insatisfatório de publicações e trabalhos acadêmicos, destacando-se nos últimos anos os trabalhos de Eliane 
Esse desconhecimento mútuo produz uma invisibilidade. Apesar dos impactos dos feminismos sobre as religiões, o desenvolvimento de uma análise feminista das religiões, que leve em conta as diferentes formas pelas quais as relações entre os gênero moldam práticas, representações e discursos religiosos é ainda fecundo. Por sua vez, os estudos da religião não absorvem as proposições de gênero de maneira significativa e sistemática. A experiência de muitas mulheres religiosas oscila entre a afirmação de sua fé religiosa e a necessidade de defender os mais elementares de seus direitos, em busca da própria autonomia. As mulheres exigem o reconhecimento de sua capacidade moral de tomar decisões que consideram válidas dos pontos de vista ético e religioso e o reconhecimento de seu direito de decidir acerca de questões que afetem suas vidas e seus corpos (Maria José ROSADO-NUNES, 2017).

Nas escolas feministas hegemônicas, as estudiosas têm há tempos "visualizado a consciência de gênero como nascida fora da crença e da experiência religiosa” (Ann BRAUDE, 2004, p. 569). Entretanto, mulheres religiosas e religiosas feministas têm sido parte da história contemporânea dos movimentos de mulheres em todo o mundo. Ao lado das não-religiosas, elas têm lutado por seus direitos e por igualdade, enquanto também se identificam com sua fé religiosa pessoal. Uma atitude negativa no feminismo secular é abordar o estudo da relação entre religião e gênero em termos de uma única e reducionista problemática: "a religião é boa ou ruim para as mulheres?" (Linda WOODHEAD, 2001, p. 384). Há uma série de problemas com essa abordagem temática. Um deles é que a pergunta é muito ampla e muito contundente para fazer justiça às formas extremamente variadas de religião ou as maneiras sutis, complexas e altamente específicas em que as mulheres habitam, subvertem e negociam com elas. Por isso,

Gouveia, Maria das Dores Campos Machado, Cecília Loreto Mariz e Patrícia Birman (Sandra Duarte de SOUZA, 2008). Segundo o levantamento realizado pelo Grepo (Grupo de Estudos Gênero, Religião e Política), foram detectadas 95 teses e dissertações no período estudado - de 1987 a 2010 - abordando as questões de gênero e/ou feminismo e religião. Os números acima demonstram que o espaço de estudo gênero e religião e/ou feminismo e religião é em grande parte construído por mulheres (Terezinha MATOS; Lúcia da CUNHA, 2013). 
[...] a relação entre as mulheres, religião e mudança social tomou uma grande variedade de formas. As mulheres têm atuado em movimentos religiosos que eram revolucionários em suas implicações. As mulheres têm atuado em movimentos revolucionários que eram religiosos (pelo menos parcialmente) em sua inspiração. As muIheres se inspiraram individualmente na religião para participar de movimentos que lutavam por mudanças na sociedade; mulheres têm sido solicitadas a lutar por mudanças sociais e mudanças na religião. A religião tem sido um instrumento de libertação para as mulheres. Da mesma forma como se torna um instrumento de opressão social das mulheres (Yvonne YAZBECK-HADDAD, 1988, p. 21).

As mulheres podem experimentar tanto empoderamento como subordinação dentro de contextos religiosos. A religião, portanto, pode ser analisada tanto como um recurso quanto como barreira aos direitos das mulheres, ou à sua participação e pertencimento dentro e fora das comunidades religiosas. Dessa forma, os direitos das mulheres e a igualdade de gênero devem ser estudados em contextos particulares que considerem suas oportunidades e participação em uma perspectiva maior, não de forma reducionista onde só se reconhece cenários feministas, ou seja, libertadores, no seio de movimentos de mulheres seculares.

Por isso, nesse artigo foi feita uma conexão desse ativismo religioso, forte, nacional que se opõe a uma religião colonial e patriarcal com a teoria do feminismo descolonial, que é uma nova onda feminista crítica e figurou no cenário acadêmico e social a partir dos anos 2000. É uma fonte epistemológica bastante recente e trata-se de um feminismo que se produz desde a América Latina, mas não somente, superando a onda de um feminismo branco, burguês, liberal, acadêmico, institucional, secular que ocupou boa parte do espaço do movimento feminista nos últimos anos. Forma-se uma frente de diálogos que confronta e enfrenta as teses e pressupostos eurocêntricos, rompendo epistemologicamente e politicamente com o feminismo hegemônico para fazer uma leitura feminista desde o lugar das mulheres como praticantes de uma fé interpelada pelas suas experiências, conhecimentos, necessidades e visões de mundo (Anete ROESE, 2018).

As discussões sobre o feminismo descolonial têm alcançado diversas áreas do conhecimento, como a sociologia, a antropologia, a história, 
a filosofia, entre outras. Contudo, no que tange aos estudos das religiões, há pouca produção, levando-nos a considerar que a relação entre feminismo descolonial e religião ainda é uma equação pouco estudada e pesquisada nas academias brasileiras (Letícia ROCHA, 2018). Diante de uma limitação do pensamento feminista hegemônico que, muitas vezes, não reconhece a existência do feminismo religioso, e de uma falha analítica de um feminismo descolonial o qual, ainda, não estuda e pesquisa utilizando as lentes da religião, esse artigo vai fazer uma análise que repousa nos referenciais metodológicos da descolonialidade e do feminismo relacionado ao fenômeno religioso, buscando conhecer, reconhecer e dar visibilidade às mulheres religiosas que estão à margem, mas que lutam pelo reconhecimento da dignidade humana e igualdade de gênero dentro do enquadramento cristão (Anete ROESE, 2018).

O feminismo descolonial é essencial nesse contexto social brasileiro colonial, patriarcal e capitalista, pois se apresenta como uma ferramenta no âmbito dos estudos feministas, acadêmicos e, pode-se estender, para o âmbito dos estudos das religiões relativa à participação, à promoção, à visibilidade, à descoberta e ao reconhecimento das mulheres que estão à margem. É um estudo que enuncia, bem como denuncia, mulheres que são silenciadas e ocultadas por um padrão hegemônico predominante (Letícia FERREIRA, 2018). Aspira-se, com este estudo, divulgar o pensamento e as narrativas nunca contadas ou apresentadas pela história oficial de mulheres religiosas cristãs.

\section{MULHERES CRISTÃS, AÇÃO E FEMINISMO}

A originalidade no movimento das mulheres religiosas começa a ser percebida a partir do momento em que se articula às questões levantadas pelo movimento feminista. Essas questões têm a ver, em grande parte, com a violência contra as mulheres nas suas múltiplas facetas: tem a ver com o controle da sexualidade feminina, com as questões relativas à reprodução, com a questão da laicidade do Estado e outras. Mas, visto o caráter assistemático em que se apresenta (Ivone GEBARA, 2006), "a teologia feminista não é de massa, acontece a partir de grupos pequenos. Não existe proposta de melhora imediata, é uma desconstrução da teoria tradicional, para a formação de uma que seja mais libertadora" (Regina JURKEWICZ, 1997). 


\subsection{Grupos de ação, coletivos e associações}

Agora, vamos adentrar para a análise dos dados coletados: primeiramente, expõe-se o mapeamento dos grupos, coletivos, redes e associações de mulheres cristãs ou com projetos voltados para elas, desenvolvendo sobre seus objetivos, suas visões e seus principais projetos. Posteriormente, apresentar-se o perfil das organizações, chegando, por último, na sua militância.

\section{Tabela 1: Mapeamento dos grupos, coletivos e redes de mulheres cristãs}

\begin{tabular}{|c|c|c|c|c|}
\hline NOME & SOBRE & REDES & $\begin{array}{c}\text { ONDE } \\
\text { ATUAMOS? }\end{array}$ & $\begin{array}{l}\text { O QUE FAZEMOS? } \\
\text { PROJETOS }\end{array}$ \\
\hline $\begin{array}{l}\text { 1. Conselho Na- } \\
\text { cional de Igrejas } \\
\text { Cristãs no Brasil } \\
\text { (CONIC) }\end{array}$ & $\begin{array}{l}\text { O CONIC nasceu no ano de } \\
\text { 1982, em Porto Alegre (RS) } \\
\text { com o objetivo de garantir os } \\
\text { direitos humanos no âmbito } \\
\text { religioso. A organização conta } \\
\text { com homens e mulheres, na } \\
\text { diretoria uma mulher ocupan- } \\
\text { do lugar de vice-presidente } \\
\text { e possui um braço organi- } \\
\text { zacional de mulheres e para } \\
\text { mulheres. }\end{array}$ & Nacional & Brasil & $\begin{array}{l}\text { - Fala em eventos; } \\
\text { - Eventos; } \\
\text { - Oficinas e capacitação; } \\
\text { - Campanhas; } \\
\text { - Assistência; } \\
\text { - Década Ecumênica de } \\
\text { Solidariedade das Igrejas } \\
\text { com as Mulheres } \\
\text { (1988-1998)'. }\end{array}$ \\
\hline 2. Projeto Raabe & $\begin{array}{l}\text { É um grupo de atendimento } \\
\text { a mulheres em situação de } \\
\text { violência da Igreja Universal } \\
\text { do Reino de Deus, desde } 2011 . \\
\text { O foco é no atendimento } \\
\text { jurídico e psicológico. }\end{array}$ & Nacional & Brasil & $\begin{array}{c}\text { - Cursos; } \\
\text { - Atendimento } \\
\text { profissional; } \\
\text { - Atuação nos presídios². }\end{array}$ \\
\hline
\end{tabular}

A Década teve papel importante ao evidenciar um "ecumenismo feminino, prático, de defesa da vida", de uma espiritualidade ecumênica e partilha de conhecimentos, ajudando a "abrir horizontes nas questões de gênero e nas possibilidades de mais justiça e solidariedade das igrejas em relação às mulheres". Tanto a ordenação feminina ao ministério como a representatividade das mulheres em diversas instâncias eclesiásticas ou da sociedade civil refletem os objetivos da década (Sybila BASKE, 2001, p. 35)

O Projeto promove o Curso Autoconhecimento para o desenvolvimento da autoestima, com o objetivo ajudar mulheres a tomarem consciência das suas metas, desejos e ter controle sobre suas emoções. Possui o Atendimento Profissional com orientação jurídica e social para mulheres que sofrem violência doméstica e abuso (cf. http://www. godllywood.com/projetoraabe/). 


\begin{tabular}{|c|c|c|c|c|}
\hline NOME & SOBRE & REDES & $\begin{array}{c}\text { ONDE } \\
\text { ATUAMOS? }\end{array}$ & $\begin{array}{l}\text { O QUE FAZEMOS? } \\
\text { PROJETOS }\end{array}$ \\
\hline $\begin{array}{l}\text { 3. Coletivo } \\
\text { Vozes Marias }\end{array}$ & $\begin{array}{l}\text { O Coletivo começou em } 2014, \\
\text { e é uma organização não } \\
\text { governamental que surgiu } \\
\text { no interior da Rede FALE/ } \\
\text { Recife agregando pessoas e } \\
\text { organizações comprometidas } \\
\text { com os princípios e valores } \\
\text { do Evangelho de Jesus Cristo, } \\
\text { debruçando-se sobre os estu- } \\
\text { dos de gênero. }\end{array}$ & Local & Recife & $\begin{array}{c}\text { - Presta assessoria e } \\
\text { consultoria à igrejas e } \\
\text { organizações diversas na } \\
\text { temática de gênero; } \\
\text { - Desenvolve ações e pro- } \\
\text { jetos de cunho educativo } \\
\text { e político } 3 \text {. }\end{array}$ \\
\hline $\begin{array}{l}\text { 4. Evangélicas } \\
\text { pela Igualdade } \\
\text { de Gênero (EIG) }\end{array}$ & $\begin{array}{c}\text { Fundado em 2015, o grupo EIG } \\
\text { tem como objetivo discutir } \\
\text { temas relacionados à violência } \\
\text { contra a mulher e à igualdade } \\
\text { de oportunidades nas estrutu- } \\
\text { ras religiosas. Atua também na } \\
\text { perspectiva da interseccional } \\
\text { idade de gênero-classe-raça/ } \\
\text { etnia. }\end{array}$ & Nacional & São Paulo & $\begin{array}{c}\text { - Fala em eventos; } \\
\text { - Eventos; } \\
\text { - Oficinas e capacitação; } \\
\text { - Campanhas, como a } \\
\text { “Meu corpo, minha fé”; } \\
\text { - Seminários; } \\
\text { - Produção de conteúdo; } \\
\text { - Assistência } \\
\text { Jurídica4. }\end{array}$ \\
\hline $\begin{array}{l}\text { 5. Projeto } \\
\text { Redomas }\end{array}$ & $\begin{array}{l}\text { Organização criada em } 2015 \\
\text { que busca dar voz às mulheres } \\
\text { que sofrem violências e com } \\
\text { o machismo em espaços de } \\
\text { fé cristã. }\end{array}$ & Nacional & On-line & $\begin{array}{l}\text { - Produção de conteúdo; } \\
\text { - Campanhas: (in)visíveis, } \\
\text { mulheres da bíblia e nós; } \\
\text { - Eventos } 5\end{array}$ \\
\hline $\begin{array}{c}\text { 6. Católicas } \\
\text { pelo Direito de } \\
\text { Decidir }\end{array}$ & $\begin{array}{c}\text { É uma ONG que chegou ao } \\
\text { Brasil em } 1993 \text { e trabalha } \\
\text { junto ao movimento feminista } \\
\text { para que mulheres tenham } \\
\text { liberdade para decidir sobre } \\
\text { seus direitos individuais - } \\
\text { relacionados à sexualidade, } \\
\text { maternidade ou igualdade de } \\
\text { gênero. }\end{array}$ & $\begin{array}{l}\text { Internacio- } \\
\text { nal }\end{array}$ & $\begin{array}{l}\text { Brasil, Argentina, } \\
\text { Bolívia, Chile, } \\
\text { Colômbia, Equa- } \\
\text { dor, El Salvador, } \\
\text { México, Nicarágua, } \\
\text { Paraguai, Peru e } \\
\text { Espanha }\end{array}$ & $\begin{array}{c}\text { - Advocacy; } \\
\text { - Oficinas; } \\
\text { - Cursos; } \\
\text { - Assessorias; } \\
\text { - Rede de multiplicadoras } \\
\text { católicas; } \\
\text { - Produção acadêmica } \\
\text { - Movimento } \\
\text { \#FÉministas }{ }^{6} \text {. }\end{array}$ \\
\hline
\end{tabular}

3 O coletivo faz seu trabalho pautado na formação, intervenção e produção de conhecimento no campo da justiça de gênero e dos direitos humanos das mulheres (cf. https://vozesmarias.wordpress.com/).

4 A campanha "Meu Corpo, Minha fé" acontece via acolhimento e assistência jurídica de qualquer mulher que sofreu alguma agressão ou abuso dentro da sua comunidade de fé por aqueles que utilizam seu "status espiritual" ou algum tipo de liderança (cf. https://www.facebook.com/mulhereseig/videos/151235819223 4907/).

5 O projeto é responsável por uma produção enorme de conteúdos sobre assuntos, que incluem a violência de gênero em espaços de fé e a visibilidade de mulheres bíblicas nas igrejas, por exemplo. Hoje já tem os mais diversos conteúdos: textos, podcasts, artes e fotografia. A campanha "mulheres da bíblia e nós" busca mostrar exemplos de mulheres fortes na Bíblia (cf. http://projetoredomas.com/).

6 São encontros periódicos organizados em parceria com a Koinonia Presença Ecumênica ideia, para dar prosseguimento às nossas reflexões sobre intolerância religiosa, resistência feminista, Estado laico, et. (cf. https://www. facebook.com/events/2298502493812124/). 


\begin{tabular}{|c|c|c|c|c|}
\hline NOME & SOBRE & REDES & $\begin{array}{c}\text { ONDE } \\
\text { ATUAMOS? }\end{array}$ & $\begin{array}{l}\text { O QUE FAZEMOS? } \\
\text { PROJETOS }\end{array}$ \\
\hline $\begin{array}{l}\text { 7. Centro de } \\
\text { Estudos Bíblicos } \\
\text { (CEBI) }\end{array}$ & $\begin{array}{l}\text { É uma associação fundada em } \\
\text { 1979, formada por mulheres } \\
\text { e homens de diversas } \\
\text { denominações cristãs para } \\
\text { divulgar, aprimorar e capacitar } \\
\text { pessoas no uso dessa forma } \\
\text { nova de ler e interpretar a } \\
\text { Bíblia. }\end{array}$ & Nacional & Brasil & $\begin{array}{c}\text { - Leitura Feminista da } \\
\text { Bíblia; } \\
\text { - Publica autoras que } \\
\text { ampliam as reflexões } \\
\text { sobre os textos sagra- } \\
\text { dos através da teologia } \\
\text { feminista; } \\
\text { - Programa de Formação7; }\end{array}$ \\
\hline $\begin{array}{l}\text { 8. Feminismo } \\
\text { Cristão }\end{array}$ & $\begin{array}{l}\text { Início em } 12 \text { de junho de } 2015 \\
\text { busca ser um espaço para se } \\
\text { discutir as interseções de ser } \\
\text { mulher, religiosa e feminista. }\end{array}$ & Nacional & On-line & $\begin{array}{l}\text { - Produção de conteúdo; } \\
\text { - Grupos de Discursão on- } \\
\text {-line e seguros; }\end{array}$ \\
\hline $\begin{array}{l}\text { 9. Feministas } \\
\text { Cristãs }\end{array}$ & $\begin{array}{l}\text { É um grupo do Facebook que } \\
\text { ajuda as mulheres religiosas a } \\
\text { lidar com os dilemas de quem } \\
\text { tenta conciliar as duas posi- } \\
\text { ções: feminista e cristã. }\end{array}$ & Nacional & On-line & $\begin{array}{c}\text { - Grupos de Discursões } \\
\text { On-line; }{ }^{9}\end{array}$ \\
\hline 10. Diaconia & $\begin{array}{l}\text { É uma ONG fundada em } 1967 \\
\text { que atua na promoção e } \\
\text { defesa dos direitos humanos } \\
\text { nos estados de Pernambuco, } \\
\text { Rio Grande do Norte e Ceará. }\end{array}$ & Local & $\begin{array}{l}\text { Pernambuco e } \\
\text { Fortaleza }\end{array}$ & $\begin{array}{l}\text { - Projeto "JUSTIÇA DE } \\
\text { GÊNERO E IGREJAS" }\end{array}$ \\
\hline
\end{tabular}

7 O CEBI promove, à nível local a Leitura Feminista da Bíblia, afinal o texto bíblico é marcado pelo patriarcalismo, seja na sua origem, seja na tradição interpretativa das igrejas. A leitura feminista da Bíblia quer desconstruir, renomear e reconstruir a memória esquecida das mulheres; à nível nacional, realiza o Programa de Formação, a cada dois anos, em 2001, realizou-se o primeiro encontro de Capacitação de Leitura de Gênero e Hermenêutica Feminista (cf. https://cebi.org.br/).

8 Nos limites "seguros" da comunidade, elas falam sobre passagens da Bíblia que consideram machistas ou feministas, compartilham vídeos "problemáticos" das suas próprias igrejas, mas também exaltam pastores e padres considerados progressistas e tiram dúvidas sobre doutrinas religiosas (cf. https://www.face book.com/feminismocristao/).

9 O grupo contava com mais de 960 pessoas que querem ser respeitadas por serem feministas e cristãs. Segundo Thayô Amaral, criadora do grupo, era importante ter um espaço onde mulheres cristãs feministas sejam aceitas, "no grupo, podemos discutir coisas que não conseguimos nem no meio feminista, por sermos cristãs, e nem no meio cristão, onde sofremos bastante rejeição" (cf. https://planofeminino.com.br/ publicitaria-goiana-cria-grupo-de-feministas-cristas-para-combater-duplo-preconceito/).

10 As ações contemplam formações sociopolíticas (oficinas, rodas de diálogos, seminários), campanhas e produção de conteúdo educativo, como cartilhas que facilitam a abordagem da temática nas igrejas. Lideranças cristãs também são estimuladas a se tornarem referência no acolhimento, acompanhamento e encaminhamento de mulheres vítimas de violência doméstica (cf. http://bemvindo.diaconia.org.br/60/Justi \%C3\%A7a-de\%20g\%C3\% A Anero\%20e\%2oigrejas). 


\begin{tabular}{|c|c|c|c|c|}
\hline NOME & SOBRE & REDES & $\begin{array}{c}\text { ONDE } \\
\text { ATUAMOS? }\end{array}$ & $\begin{array}{c}\text { O QUE FAZEMOS? } \\
\text { PROJETOS }\end{array}$ \\
\hline $\begin{array}{l}\text { 11. Frente } \\
\text { Evangélica Pela } \\
\text { Legalização do } \\
\text { Aborto }\end{array}$ & $\begin{array}{l}\text { Foi criada em } 2017 \text { e é uma } \\
\text { frente de luta pelo direito } \\
\text { das mulheres que afirma que } \\
\text { existe, dentro das igrejas, } \\
\text { enfrentamento a essa lógica } \\
\text { de morte estabelecida pelo } \\
\text { fundamentalismo. }\end{array}$ & Local & Rio de Janeiro & $\begin{array}{l}\text { - Eventos; } \\
\text { - Posicionamento público; } \\
\text { - Falas em eventos; } \\
\text { - Produção de conteúdo; } \\
\text { - Seminário: “Cristianismo } \\
\text { e a descriminalização do } \\
\text { aborto”" }\end{array}$ \\
\hline $\begin{array}{l}\text { 12. Koinonia Pre- } \\
\text { sença Ecumêni- } \\
\text { ca e Serviço }\end{array}$ & $\begin{array}{l}\text { É uma organização fundada } \\
\text { em } 1994 \text { tem como objetivo } \\
\text { mobilizar a solidariedade } \\
\text { ecumênica e prestar } \\
\text { serviços a grupos histórica e } \\
\text { culturalmente vulneráveis e } \\
\text { em processo de emancipação } \\
\text { social e política. }\end{array}$ & Local & São Paulo & $\begin{array}{c}\text { - Rede Religiosa de Pro- } \\
\text { teção à Mulher Vítima de } \\
\text { Violência; } \\
\text { - Direitos das Mulheres e } \\
\text { da População LGBTT; } \\
\text { - Roda de Diálogo: } \\
\text { Religião, Corporeidade } \\
\text { Direitos Reprodutivos; }\end{array}$ \\
\hline $\begin{array}{l}\text { 13. Rede Ecumê- } \\
\text { nica da Juventu- } \\
\text { de (REJU) }\end{array}$ & $\begin{array}{c}\text { É uma rede formada e } \\
\text { protagonizada, em } 2007 \text {, } \\
\text { pelas juventudes no Brasil que } \\
\text { buscam, a partir de distintas } \\
\text { formas de espiritualidades, a } \\
\text { promoção dos direitos juvenis. }\end{array}$ & Brasil & Nacional & $\begin{array}{l}\text { - Produção científica de } \\
\text { conteúdo; } \\
\text { - Participação em Con- } \\
\text { gressos, Conferências }{ }^{13} ;\end{array}$ \\
\hline $\begin{array}{l}\text { 14. Combate ao } \\
\text { Abuso no Meio } \\
\text { Espiritual - } \\
\text { COAME }\end{array}$ & $\begin{array}{l}\text { É um movimento criado em } \\
2018 \text { de sobreviventes a diver- } \\
\text { sas formas de abuso no Meio } \\
\text { Espiritual. }\end{array}$ & Nacional & Brasil & - Plataforma Coame;14 \\
\hline $\begin{array}{l}\text { 15. Rede de Mu- } \\
\text { Iheres Negras } \\
\text { Evangélicas }\end{array}$ & $\begin{array}{l}\text { Surgiu em } 2018 \text { com objetivo } \\
\text { dearticular ações e fomentar a } \\
\text { mobilização das mulheres ne- } \\
\text { gras evangélicas em todo Brasil. }\end{array}$ & Local & $\begin{array}{l}\text { Distrito Federal, Rio } \\
\text { de Janeiro, Bahia e } \\
\text { Pernambuco }\end{array}$ & $\begin{array}{c}\text {-Encontro de Mulheres } \\
\text { Negras Cristãs }{ }^{15}\end{array}$ \\
\hline
\end{tabular}

É um seminário que vai debater sobre os desafios e possibilidades da Arguição de descumprimento de preceito fundamental $n^{\circ} 442 \mathrm{com}$ relação ao cristianismo e as igrejas brasileiras (cf. https://www.face book.com/ events/320999975108521/).

12 A Rede Religiosa de Proteção à Mulher Vítima de Violência desenvolve ações para proteção, articulação, mobilização e proposição de políticas públicas específicas para as mulheres, atuando junto à rede de enfrentamento à violência contra as mulheres; debates com homens e mulheres sobre enfrentamento a violência contra as mulheres nas comunidades religiosas, com diferentes parceiros da sociedade civil e órgãos públicos (cf. http://koinonia.org. br/2763-2). Já a roda se propõem a falar de "Religião, Corporeidade e Direitos Reprodutivos" tarefa urgente em nosso complexo tempo de avanços e retrocessos neste campo, sobretudo quando se trata dos usos, desusos e abusos da religião em relação aos corpos das mulheres, tem a proposta de ampliar o debate acerca dessa temática a partir de olhares dos cristianismos (cf. https://www.facebook.com/events/373158226871882/).

13 Na Rede existem cinco eixos temáticos de ação que foram pensados a fim de dar conta da promoção dos direitos juvenis, sendo um desses "Juventudes, sexualidades e lutas feministas" (cf. http://reju.org.br/).

14 É uma ferramenta que concentra denúncias de violações sexuais cometidas por padres, pastores, gurus e congêneres, a comunicação é feita por e-mail diretamente no site da organização (cf. http://coamebr.tk/).

15 É um encontro que promove a leitura popular e feminista e da bíblia desde uma perspectiva antirracista e antissexista e fortalece a incidência pública através da organização coletiva das mulheres negras evangélicas, privilegiando a importância do trabalho em rede (cf. http://twixar.me/wt6n). 


\subsection{Perfil das organizações}

A partir da tabela acima, é possível observar uma variedade de mobilização que está sendo desenvolvida, impulsionadas por uma mistura de pessoas, redes formais e movimentos informais. Nesse momento, após um contato mais próximo com os espaços selecionados acima, foi possível perceber tendências gerais relacionadas ao perfil desses grupos e é exatamente sobre ele que as próximas partes do trabalho vão se destrinchar. Preocupou-se com: 1) a classificação dos grupos, no caso, se é um grupo feminista ou se é de advocacy; 2) com as principais formas de ação e trabalho desenvolvidas; 3 ) como se identificam enquanto denominação religiosa; 4) qual o potencial de mobilização; e 5) se o contexto de atuação é nacional ou local, ou seja, se descreve como as mulheres cristãs percebem e participam da construção dos seus direitos.

1. Inúmeros são os grupos e associações que compõem a sociedade civil. Por isso, criou-se, para este trabalho, uma classificação específica, de acordo com a orientação e propósito principal de união dessas mulheres ${ }^{4}$. Em relação às associações estudadas: $42,8 \%$ se enquadram como grupos feministas; $32 \%$ nos conselhos; $14,2 \%$ nos centros de estudos; $14,2 \%$ em advocacy; $14,2 \%$ nas relações públicas.

2. As principais formas de ação e trabalho dentro desses grupos também são bastante diversas. Entretanto, pode-se colocar como inclinações principais: 2.a) Advocacy; 2.b) Fala em Eventos; 2.c) Eventos; 2.d) Campanhas; 2.e) Produção de Recursos; 2.f) Pesquisa; (2.g) Oficinas/ Capacitações; (2.h) Grupos de Ajuda; (2.i) Assistência; 2.j) Assessoria; 2.k) Fórum on-line; 2.I) Grupos de Discursão.

\footnotetext{
É possível elencar sete tipos: (1.a) relações públicas, se estão ativamente envolvidos em quebrar estereótipos e promover uma imagem positiva das mulheres; (1.b) conselhos, são grupos na comunidade onde as mulheres oferecem espaço para socializar e compartilhar interesses femininos e preocupações, cuidar de necessidades das crianças; (1.c) advocacy, são grupos que trabalham em particular contra discriminação étnica, racial e religiosa; (1.d) centros de estudos da religião, grupos que se reúnem para aprender a fé e também se envolver no trabalho caritativo, programa de educação infantil, atividades sociais e festividades; (1.e) suporte, são grupos de apoio para as mulheres que sofreram alguma violência/descriminação; (1.f) tradição cultural, são grupos preocupados em manter tradições culturais a partir de formas artísticas religiosas; (1.g) feministas, são grupos dedicados a construir uma igualdade de gênero.
} 


\section{Tipos de Organizações}

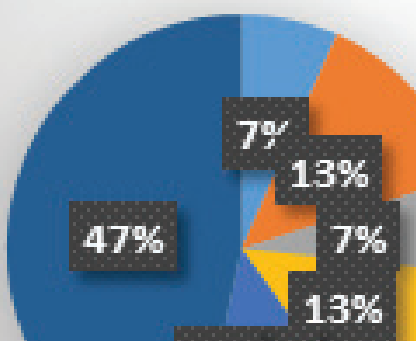

Consehos

Relações Públicas

Advocacy

Centro de Estudos

$0 \% 3 \%$

Suporte

tradição Cu tural

Fonte: elaborado pela autora (2019).

3. No âmbito dos espaços não existe diferenciação pela denominação religiosa, ou quando existe e é pontuada, a organização se mostra como aberta a amplitude e vertentes da identidade cristã. Esse resultado, está de acordo com a teoria do discurso de Laclau (1985), a qual não foi trabalhada nesse artigo, mas afirma que diante de um "outro" de fala mais forte ocorre a diminuição da diferenciação interna dentro do movimento no qual se opõe. Ou seja, o "outro" sendo secular e/ou a igreja cristã oficial, faz com que a heterogeneidade dentro de ser cristã (católica, protestante, pentecostal, etc.) seja articulada em oposição a um poder comum e opressivo. Por isso, entre os grupos pesquisados, por exemplo, no coletivo feminista "Católicas pelo Direito de Decidir" elas enquanto movimento fazem associação a Igreja Católica, mas afirmam que fazem parte da composição do grupo mulheres de todas as correntes cristãs, ou seja, as organizações que lidam diretamente com a comunidade de mulheres cristã podem até formalmente se posicionarem ligadas a uma corrente específica, mas não acham importante limitar o trabalho ou participação de mulheres de outras denominações. 


\section{Enquadramento religioso}

Fonte: elaborado pela autora (2019).

4. Com intuito de perceber o potencial de mobilização, nesse caso, foi utilizada uma única fonte de dados padrão. No caso, retirou-se só os quantitativos de seguidores do Facebook e criou-se um nível de alcance para diminuir os erros de mensuração, pelo fato de existir uma variação muito grande no quantitativo desses grupos. Existe coletivo, por exemplo, que conta com 40.000 seguidores e outro com 308 pessoas. Fixou-se então, a) nível 1: 0 - 500 pessoas; b) nível 2: $501-1.000$ pessoas; c) nível 3: 1.001 - 5.000 pessoas; d) nível 4: 5.001-10.000 pessoas; e e) nível 5: 10.001- 50.000 pessoas. Dentro das organizações, foi percebido que a maioria delas, $60 \%$, tem um alcance de nível 3 ou 4, ou seja, o máximo que elas conseguem comunicar-se diretamente é entre 1.001 até 10.000 pessoas.

5. Já em relação ao contexto de mobilização, elas têm lugar em dois níveis: o nacional (60\%) e o local (40\%), ou seja, tanto localmente dentro das cidades ou estados como crescendo para além deles. Viu-se também que apenas Católicas Pelo Direito de Decidir e o Projeto Raabe, ou seja, $13 \%$ se articulam internacionalmente. Os dois grupos estão na América Latina, nos Estados Unidos e na Europa, trabalhando de forma 
articulada com os mesmos propósitos. Percebe-se também que dos coletivos com atuação local, mais da metade deles são grupos feministas que surgem de contextos sociais, políticos e econômicos específicos, como o Coletivo Vozes Maria que se estabelece no Recife e tem uma agenda política voltada para essa realidade. Diante disso, percebe-se grupos organizados mais nacionalmente, mas com nenhum ou quase nenhum braço internacional.

Ainda, é importante ressaltar que o perfil dessas associações é marcado por uma temporalidade.. Nesse caso, $60 \%$ das associações surgiram nos anos 2000 e 53,3\% dos anos 2011 em diante, ou seja, são organizações atuais. Das organizações acima, quase todas estão em atividade. Apenas o coletivo "Feministas Cristãs" foi desativado pela comunidade do Facebook no dia 31 de março de 2019, sob a justificativa de que possuía conteúdo que violava os Padrões da Comunidade sobre discurso de ódio. De acordo com uma das fundadoras, o grupo incomodava com discussões e críticas a comunidade religiosas e foi desativado por conta de denúncias (cf. http://twixar.me/grQn). Apenas um único coletivo, a "Rede de Mulheres Negras Evangélicas", faz a militância também pelo recorte de raça. E apenas 30\% desses grupos realizam trabalhos dentro das igrejas: Raabe, Diaconia, Kaionia, Conic e Reju.

Todos os espaços têm conteúdo especializado para mulheres cristãs. Também são espaços formados majoritariamente por mulheres. Deles, $80 \%$ são liderados por mulheres ou foram criados por mulheres (mas, por assumirem uma organização horizontal não nomeiam líderes), entretanto, $60 \%$ desses espaços são grupos que não estão conectados a nenhuma instituição religiosa, muito menos são defendidos pelo discurso oficial da religião, ou seja, são formados por mulheres que já não suportam mais estar nesses espaços institucionais, mas não vão deixar de disputá-los, também confirmando o que a própria teologia feminista brasileira afirma que essa prática feminista se configura nas margens do campo institucional (Ivone GEBARA, 2006). Dessa forma, consegue-se

Quando eu comecei a me aproximar do tema, em 2018, realizei meu primeiro mapeamento das organizações e coletivos e o "Feministas Cristãs" estava em funcionamento, diante de ter sido possível coletar dados relacionados a objetivo, organização, ação e projetos da página achei importante deixar como objeto de estudo. 
perceber que são uniões formadas de maneira significativa pelo protagonismo feminino, onde as mulheres cristãs trabalham para e por elas.

\subsection{Militância}

Depois de feita uma primeira apresentação sobre a organização dentro dos espaços de ação das mulheres cristãs, é o momento de dedicar atenção às principais preocupações e tendências de pensamento das mulheres cristãs no Brasil. Constitui parte da militância dessas mulheres: 1 ) defender a ordenação feminina; 2 ) lutar pelo fim da violência contra a mulher no âmbito institucional e da violência de gênero silenciada pela fé; 3) luta pelos direitos reprodutivos e sexuais, em especial a pauta pela descriminalização do aborto; 4) denuncia ao fundamentalismo religioso que invade a nossa política e, em paralelo, defesa da laicidade do Estado.

1. O debate sobre o a ocupação das mulheres nos postos de poder dentro das igreja é uma pauta quase que fundadora do movimento religioso feminista. Desde os primórdios, as mulheres religiosas estavam insatisfeitas por serem relegadas aos espaços administrativos de cuidado, limpeza e trabalhos educativos. Afinal, as mulheres são maioria nas igrejas, por que devem ser guiadas por uma liderança minoritária de homens? É notório que as mulheres, cada vez mais, participam em funções de liderança na sociedade, por que não nas igrejas? Por isso, na atualidade, é importante perguntar qual o lugar das mulheres nos espaços religiosos e se as comunidades são espaços seguros de acolhida ou de legitimação das violências.

Dessa forma, o posicionamento dos grupos em relação a esse tema se estabelece através de duas formações discursivas: a primeira, direcionada à igreja enquanto instituição; e a segunda, propagada para as próprias mulheres cristãs. É de entendimento dessas mulheres a importância de se posicionar através dessas duas vias, exatamente porque o primeiro discurso busca confrontar e descontruir o poder institucionalizado patriarcal cristão que ainda não aceita e fortemente dificulta a entrada da mulher em cargos de liderança. Ao mesmo tempo que um segundo discurso é responsável por acolher as mulheres religiosas e reconhecer que elas não precisam estar dentro desses espaços, pois 
sabe-se que o ambiente institucional da fé não é seguro, nem para elas, nem para suas crianças. Dessa forma, o discurso caminha em mão dupla, combatendo a estrutura patriarcal cristã, de um lado, e acolhendo e reconfortando as mulheres sobre a realidade.

A formação discursiva contrária à estrutura patriarcal das igrejas é comum dentro de Católicas pelo Direito de Decidir, que se afirmam contrárias ao "machismo eclesial através da composição masculina do clero católico, formado por padres, bispos, cardeais e papa, que fomenta a manutenção do poder masculino e exclui ou deixa em posições subalternas as mulheres e as religiosas" (cf. http://twixar.me/7PNn). O Projeto Redomas utiliza de argumentos bíblicos para construir seu discurso contrário às desigualdades, tanto que afirmam:

Jesus não mantinha as mulheres à sua volta como uma forma de suporte apenas ou como coadjuvantes nos seus planos e do Pai. Jesus delegava a elas papéis importantes do seu ministério e confiava nelas para ajudá-lo a cumprir a obra de Deus, tendo sempre uma disposição enorme para ensiná-las e introduzi-las em debates teológicos (PROJETO REDOMAS, cf. http://twixar.me/pCQn).

Mulheres reivindicam um outro lugar dentro da Igreja, adequado àquilo que elas são e fazem para a religião. Elas são fiéis, trabalham para Igreja, dão um trabalho voluntário enorme e não tem reconhecimento formal, não tem um lugar adequado (CDD, cf. http://twixar.me/7PNn).

No Brasil, diante dessas articulações feministas já existem denominações protestantes históricas que estão ordenando mulheres, como a Igreja Metodista do Brasil (Luciana Pessanha Lacerda dos Santos em 2014), a Igreja Evangélica de Confissão Luterana do Brasil (Edna Moga Ramminger em 1982) e a Igreja Episcopal Anglicana do Brasil (Carmen Etel Alves Gomes em 1985). Também é possível visualizar mulheres pastoras na Igreja Presbiteriana Independente do Brasil (Lucilêde Pereira em 2000) e na Convenção Batista Brasileira (Luciana Pessanha Lacerda dos Santos em 2014). As mulheres também ocupam posições de liderança em denominação evangélicas como o Exército da Salvação (fundada por William e Catherine Booth em 1865 na Inglaterra), Igreja do Evangelho Quadrangular (fundada por Aimee McPherson em 1923 
nos Estados Unidos), Episcopal Anglicana (Barbara Harris foi a primeira bispa em 1989 nos Estados Unidos), Evangélica de Confissão Luterana (Margot Käßmann foi a primeira pastora em 1985 na Alemanha) e uma infinidade de comunidades de pentecostais livres (Elias WOLFF, 2017).

Como exemplificado acima, essas tomadas de poder acontecem com o reconhecimento e a exposição de que, no dia a dia, muitas delas são vítimas de abuso sexual (Regina JURKEWICZ, 2006). Fica claro nos discursos:

As mulheres quando sofrem algum tipo de abuso e violência, sofrem com o silenciamento, culpabilização e até mesmo, com a omissão daquele espaço, que deveria ser de acolhida. Sem falar nas violências institucionalizadas dentro dos mesmos espaços, onde líderes manipulam a fé e cometem abusos psicológicos contra a vida das mulheres de fé" (KOINONIA, cf. http://twixar.me/hyxn).

Fazemos um movimento importante de reunir essas mulheres que não suportam mais estar nesse espaço, mas que não vão deixar de disputá-los" (CPDD, http://twixar.me/7PNn).

2. Elas defendem o fim da violência no meio espiritual, a qual atinge preferencialmente mulheres e crianças, como também querem o fim da violência de gênero. As transgressões de sacerdotes católicos ao celibato e a constatação de que comportamentos sexualmente abusivos por parte desses sacerdotes contra crianças e mulheres não é um fato novo. No entanto, o silêncio que envolve tal problemática dificulta o debate sobre o tema. O informe Maura O’Donohue aponta 23 países em que freiras foram estupradas ou sofreram algum tipo de violência sexual cometida por sacerdotes, e o Brasil está entre esses países. Mas, ainda assim, a discussão sobre abuso e violência de religiosos contra mulheres ainda está bastante incipiente (Regina JUREKEWICZ, 2006). Diante dessa realidade, surge um movimento de sobreviventes das diversas forma de abuso no meio espiritual, a Coame, elas afirmam que:

Juntas, estamos unindo nossas forças e nossas vozes para acabar com as violências no meio espiritual com crianças, jovens e adultos por parte de líderes espirituais e seus discípulos que por tempo 
demais têm silenciado vítimas e permanecido intocados (cf. http:// twixar.me (g6Qn).

Eu venho reforçar a importância sobre o assunto de relatar, mesmo que seja de forma anônima e isso vai ser respeitado por aquelas que fazer parte da força tarefa. E por que é importante isso? É possível que muitas de vocês acreditem na justiça de ver que de fato as leis são cumpridas no país e que estupradores vão para cadeia... A gente sabe muito bem como é essa dor, a gente sabe que cada uma vai no seu tempo, que muitas de vocês nunca tiveram no ministério, vocês não precisam ficar nervosas, não tenham medo, o anonimato vai ser respeitado e você está ajudando outras mulheres não passarem por isso (Vídeo: Sabrina de Campo, cf. http://twixar.me/86Qn).

O vídeo acima, "Sabrina de Campo", foi publicado na página oficial do Facebook do grupo COAME - Combate ao Abuso no Meio Espiritual, no dia 31 de janeiro de 2019. É uma peça gravada de forma independente, possivelmente com a câmera do celular, fora do estúdio, num local que aparenta ser um espaço privado. A narrativa do vídeo foi bastante ilustrativa da formação discursiva direcionada às mulheres, tanto que ela inúmeras vezes direciona sua fala a esses interlocutores (as mulheres) e busca, com esse vídeo, criar uma conversa pautada na confiança e no respeito, utilizando-se de linguagem simples do cotidiano. Sem contar que, através do reconhecimento da dor que essas mulheres estão vivenciando ou já vivenciaram, ela também garante o estabelecimento de empatia que a aproxima ainda mais da experiência real dessas mulheres.

$\mathrm{Na}$ filmagem de seus sete minutos com enquadramento em Sabrina, ativista dos direitos das mulheres, ela porta uma vestimenta simples, blusa branca, casaco preto, colar no pescoço e o cabelo está preso de qualquer jeito, sem muita preocupação. Ela se expressa com uma entonação de calma, ao mesmo tempo que a toda hora chama atenção das mulheres e da urgência de denunciar, orientando toda a sua narrativa para a comunidade de mulheres que sofrem com esses abusos, no sentido de que reconhecer e denunciar os crimes são partes essenciais nessa luta. De forma geral, a fala de Sabrina está alinhada para a desconstrução do discurso que não reconhece os incidentes ou que não pune os perpetradores, exibindo-se de uma consciência clara da importância de 
falar sobre os crimes como o intuito de alertar os governos e acarretar em políticas públicas para assegurar essa comunidade.

O recurso de produzir e compartilhar peças de audiovisual é bem recorrente dentro das organizações analisadas. Existe sim um ativismo criativo apoiado nessa ferramenta e com a participação em canais de vídeo como Youtube e Vimeo. As peças de audiovisual são extremamente ricas, pois são resultados de inúmeros componentes como imagem, som, texto, montagem, etc. É um recurso onde a conexão estabelecida através da linha de comunicação (transmissor e receptor) se expande muito, possibilitando uma interação muito maior entre os dois polos, afinal, ela pode mais facilmente sensibilizar, emocionar, revoltar, etc. A montagem vai ser responsável por conduzir a informação de uma maneira que consiga transmitir o que deseja (Maria VIEIRA, 2018). Nesse vídeo, uma montagem clara e sem muitos estímulos visual além de Sabrina, garantiram o foco para sua narrativa.

É importante também ressaltar que quando as organizações utilizam esse recurso e divulgam os abusos dentro da igreja, as ativistas dão nome e rosto ao problema. Não é mais o documento oficial da organização afirmando que as mulheres, de forma essencialista, sofrem diariamente ataques. Existe a exposição clara de uma ativista que diz seu nome e ainda relata com detalhes o que pode ser feito para transpor essa realidade, ou seja, a experiência contextualiza o sofrimento. Dessa forma a mídia alternativa, é uma ferramenta muito importante, especialmente quando é produzida de forma espontânea e sem fins lucrativos para ser o contraponto, ser o contra-discurso midiático e dos grandes conglomerados informativos que, muitas vezes retratam, e reforçam visões estereotipadas das mulheres religiosas e das comunidades que não ajudam em nada nas suas lutas diárias.

No vídeo, fica claro que existe a instauração de uma força tarefa que recebe o nome de "Somos Muitas". Essa frente de ação foi criada após as primeiras denúncias contra o médium João de Deus ao Ministério Público de Goiás (MP-GO) e conta com quatro promotores, seis delegados e duas psicólogas para atenderem e acolherem as vítimas. $O$ MP-GO já realizou o atendimento a mais de 200 mulheres que afirmam ter sido abusadas sexualmente por João de Deus, ou, João Teixeira de 
Faria, que está sendo acusado por diversas mulheres de abuso sexual durante os atendimentos espirituais na Casa Dom Inácio de Loyola, em Abadiânia, interior de Goiás. Diante da ação dessa força tarefa junto com o MP-GO, o médium está preso em Goiânia desde o dia 16 de dezembro de 2018.

Se faz necessário que nossas igrejas encarem de fato esse fenômeno social - o da violência contra as mulheres. Enxergar o problema com maturidade é reconhecer que os evangélicos, os fiéis das nossas igrejas, inclusive a liderança se envolvem em comportamentos violentos contra as mulheres, sejam elas suas namoradas, companheiras, filhas, esposas, ex esposas. É pernicioso que igrejas dê respaldo, em nome de Deus, ou da família, à quaisquer tipos de violência contra as mulheres silenciando-as em suas igrejas ou respaldando, protegendo, acobertando os homens que as violentam (EVANGÉLICAS PELA IGUALDADE DE GÊNERO, cf. http://twixar.me/nHQn).

O meu rompimento com a minha comunidade de fé se deu porque eu entendo que nesses processos de violência da Igreja contra muIheres, a igreja precisa ser protagonista e tem algumas igrejas que assumem um protagonismo (COLETIVO VOZES MARIAS, cf. http:// twixar. me/VqQn).

O recorte do áudio acima, "Fé e feminismo", é uma peça de vinte e cinco minutos e foi publicada no Facebook do coletivo Evangélicas pela Igualdade de Gênero no dia 24 de maio de 2019, mas quem participa e fala das violências é uma integrante do coletivo Vozes Marias, no Recife. O discurso foi todo estruturado na falta de pronunciamento e de protagonismo das igrejas em matéria de combater essas práticas e como isso pode levar à saída de mulheres desses espaços. Dessa forma, dialoga com a narrativa de que existe, sim, um rompimento com as igrejas, não com a fé, quando situações como essas continuam acontecendo e nada é feito pelos líderes oficiais. Todavia, pontua, a partir do local de fala delas (a matéria foi gravada em Frente ao Fórum de Justiça de Olinda), no momento em que um padre da Igreja Batista estava sendo julgado por estuprar uma fiel da sua igreja, que existe um movimento que vai proteger e amparar essas mulheres, mais que isso, uma ajuda de fé. O posicionamento da integrante foi feito de forma tranquila, não 
demostrou nenhuma alteração de humor, nem de entonação, mostrou-se confiante que a justiça seria cumprida.

Dessa forma, os discursos das mulheres cristãs já partem da afirmação que as mulheres religiosas, assim como as mulheres seculares, são vítimas de violência. Existe, então, uma frente de união para contrapor qualquer narrativa que dite o contrário, por isso, elas dirigem suas falas mais fortemente para dentro da comunidade de fé e para os discursos dentro desses espaços, proferidos por lideranças religiosas, de que a violência não acontece no âmbito da igreja. Por isso, da mesma forma que se unem ao movimento maior em defesa das mulheres e contra as desigualdades de gênero que acarretam em violências para com as mulheres, de forma mais assertiva seu discurso é proferido contra a igreja e a cultura de impunidade, silenciamento e propagação de violência. O fim da violência de gênero surge como pauta do movimento das mulheres religiosas, assim como também é e sempre foi no Brasil uma das principais reinvindicações das feministas seculares.

Dessa forma, não existe disputa em relação ao fato de que a violência de gênero existe, é real e acomete as mulheres no Brasil. Passa-se agora a especificar a narrativa que, no Brasil, 40\% das mulheres que se declaram vítimas de agressões físicas e verbais de seus maridos são evangélicas (Valéria VILHENA, 2011), e que 1/3 das mulheres que sofrem violência doméstica não fazem a denúncia formal, mas procuram meios alternativos, como as igrejas, para se abrirem e pedir ajuda (DATASENADO, 2013). Como as igrejas lidam com a experiência dessas mulheres? Silenciando-as ou pedindo que orem por seus respectivos agressores. A violência do agressor é combatida pelo poder da oração. As fraquezas de seus maridos são entendidas como investidas do demônio, então, a denúncia de seus companheiros agressores as leva a sentir culpa pois, no seu modo de entender, estão traindo seu pastor, sua igreja e o próprio Deus (Valéria VILHENA, 2011).

Assim, pergunto a vocês: a violência contra as mulheres é pecado? A resposta é sim, e não há quem possa defender, biblicamente, que um homem que bate em sua esposa, que pratica atos sexuais contra a vontade de uma mulher ou que a violenta por meio de palavras, com assédio moral e psicológico, não esteja praticando pecado (PROJETO REDOMAS, cf. http://twixar.me/BICn). 
O discurso para dentro da igreja vai ressaltar que ela é parte da comunidade maior e, da mesma forma que os homens não religiosos praticam atos de violência, homens cristãos, como parte dessa comunidade, também são agentes violentadores. Assim, vão existir cristãos que violentam suas companheiras, amigas, irmãs, mães. E constroem essa contrária discursiva utilizando da própria linguagem das igrejas, mostrando a importância de se comunicar e materializar a violência com o que os/as cristãos/ãs entendem por violência, ou seja, como pecado, e quem pratica é pecador. Indo além, trazendo elementos do discurso feminista secular da importância de ser fazer a denúncia e conectando também essa prática ao pecado, mas nesse caso, ao não pecado. A palavra pecado, então, se apresenta como uma importante ferramenta discursiva para se aproximar dos/as praticantes da fé com a linguagem da violência de gênero e assim fixar sentidos.

3. Outra pauta é o exercício pleno dos direitos sexuais e reprodutivos das mulheres. No debate coletivo sobre direitos reprodutivos no Brasil, muitas vezes, as vozes que mais se fazem ouvir são as de instituições religiosas que se opõem à autonomia das mulheres sobre o próprio corpo. Muitas atuam, inclusive dentro do Congresso Nacional, para impedir o avanço do acesso a direitos e para retroceder no que já foi conquistado, como o direito ao aborto nos casos previstos em lei (gestação decorrente de estupro, risco de morte da gestante e anencefalia fetal). O fato de as mulheres serem religiosas não as impede de interromper a gravidez. No Brasil, de acordo com a Pesquisa Nacional do Aborto, publicada em 2016, 56\% das mulheres que abortam professam a religião católica (PNA, 2016).

Por isso, entre as vozes contrárias à proibição estão as organizações formadas por mulheres religiosas, como a Católicas Pelo Direito de Decidir (CDD) e a Frente Evangélica pela Legalização do Aborto. O objetivo delas é apresentar a pessoas que compartilham sua religião a defesa da autonomia das mulheres, com base em uma interpretação do cristianismo que se contrapõe àquela que reverbera no discurso da maioria das lideranças cristãs e políticas no país. O tema voltou com força ao debate nacional desde que o Partido Socialismo e Liberdade 
(PSOL), em 2018, deu entrada no Supremo Tribunal Federal (STF) à Arguição de Descumprimento de Preceito Fundamental ADPF $n^{\circ} 442$. O partido questiona os artigos $n^{\circ} 124$ e $n^{\circ} 126$ do Código Penal, que criminalizam a prática do aborto. Todavia, é importante deixar claro uma distinção que as próprias feministas cristãs pontuam: elas são a favor da descriminalização (legalização) do aborto, não defendem o aborto em si (CPDD, http://twixar.me/1Vxn).

É necessário caminhar juntas e juntos contra os fundamentalistas. É necessário gritar em alto e bom tom, que não aceitaremos mais que nenhum dos coronéis da fé continuem a impor sobre nós, suas teologias patriarcais! Vamos descriminalizar o aborto no Brasil porque temos compromisso com a vida, e não há dogma que nos faça ceder para essa política de morte!... A laicidade não pode ser mais uma vez golpeada, reivindicamos as espiritualidades que respeitam a pluralidade e que se constroem pelo amor e autonomia da consciência e repudiamos a utilização das religiosidades para imposição e propagação do ódio FRENTE EVANGÉLICA PELA LEGALIZAÇÃO DO ABORTO, cf. http://twixar.me/4jxn).

Recortou-se parte do vídeo feito pela Frente durante a vigília inter-religiosa pela laicidade no STF em memória das mulheres mortas em abortos clandestinos, no dia 7 de agosto de 2018. O vídeo contou com 2,3 mil visualizações, 42 compartilhamentos e 36 comentários. A peça de audiovisual foi gravada na própria vigília. As mulheres ao redor estavam com velas acessas, a iluminação era pouca, mas o áudio estava em perfeito estado. O que se vê no fundo é o Congresso Nacional e, no centro, várias mulheres ativistas de diferentes grupos e coletivos. A entonação da ativista durante todo o vídeo é bastante regular, sem alterações. Pouca ou quase nenhuma gesticulação é feita e a fala é proferida com calma e clareza. Ao longo da construção do seu discurso, ela pontua sobre a importância da fé não ser desvirtuada do seu propósito maior, ou seja, proteger as pessoas, especialmente as mulheres, e ela revela os tabus e preconceitos, especialmente, quando culpa as religiosidades que seguem o caminho de dominação dos corpos femininos, ela também deixa claro sua visão de fé para com outras religiosidades possíveis, em especial aquelas que respeitam a pluralidade de consciência. 
O discurso das mulheres cristãs, representado pela ativista, se estrutura no apoio ao discurso feminista maior que também luta pela descriminalização do aborto, ancorado na saúde pública, da mesma forma que busca descontruir o discurso patriarcal da igreja "pró-vida", mas que na realidade é contrário à vida. Pois, hoje, já se sabe que o aborto clandestino é a quinta maior causa de mortalidade materna no país e que tal defesa da vida, na verdade, não existe, pois as mulheres estão morrendo, especialmente pobres, negras da periferia. De forma muito alusiva, esse vídeo é filmado em frente ao Congresso Nacional, espaço hoje dominando por forças religiosas conservadoras que defendem pautas retrógadas baseadas em dogmas religiosos. Neste sentido, a fala de uma ativista religiosa em frente a este espaço é muito representativa do entrecruzamento das forças que envolvem esses discursos, uma força de luta que se estrutura e ganha dimensão de união quando mostra que o importante é a garantia de um estado laico e de que o governo deve governar para o povo diante da necessidade dele. Dessa maneira, o estabelecimento de políticas públicas deve ser pautado nas necessidades sociais não em dogmas religiosos.

4. Aderem a posições contrárias ao fundamentalismo religioso que invade a política e a grande mídia e, em paralelo, defendem a laicidade do Estado. Roberlei Panasiewicz (2008) afirma que, nas últimas décadas, o movimento fundamentalista tem articulado religião e política como uma forma de fazer valer os valores cristãos a partir de sua concepção teológica. É dessa maneira que é possível compreender a sua forma mais atual: o neofundamentalismo. O neofundamentalismo apresenta-se não só como movimento de tipo religioso mas, também, como verdadeiro sujeito político, e sua ação está voltada para o reparo moral da sociedade através da ação política. Ao utilizar a linguagem da comunicação moderna, em especial da massa media, apresenta-se como capaz de superar as fronteiras confessionais e, por meio de uma abordagem conservadora, instiga a sociedade a recuperar o que considera valores morais do passado.

Diante desse quadro político/religioso, a militância de mulheres cristãs está pautada na fala que escancara a instrumentalização entre 
religião e política, quando denuncia a ação de bispos, pastores, padres que vem colocando sua influência religiosa para apoiar projetos políticos claramente contrários aos direitos humanos, desconstruindo narrativas que reforçam a liberação do porte de armas para a população civil, o patriarcado e a negativa de direitos às mulheres e LGBTI+. Esse discurso, da mesma forma que distancia e descaracteriza o que se diz ser religioso, pontuando a não representatividade dessas figuras em relação à comunidade cristã maior e também leva essas militantes a se aproximaram da sociedade secular na luta por direitos civis, sociais e políticos.

Somado a essa conjuntura há um avanço de um fundamentalismo religioso cristão que tem verbalizado e balizado projetos de lei que negam a igualdade de gênero e os direitos das mulheres. É importante destacar que a laicidade do Estado garante que políticas públicas e leis sejam pensadas e construídas sem quaisquer influências religiosas que se recusam a dialogar com a diversidade cultural da sociedade bem como que não reconhecem a cidadania plena das mulheres e das minorias sociais (CONIC, http://twixar.me/YBxn).

De acordo com o CONIC, no Brasil, vive-se em um Estado laico e ele é importante inclusive para a prática da fé. Busca-se garantir a laicidade porque ela assegura o respeito à diversidade cultural e religiosa, a igualdade de direitos e não legitima privilégios específicos para uma determinada tradição religiosa. Mas isso não significa que as pessoas são impedidas de se denominarem desta ou daquela tradição religiosa, nem tampouco que não tenham o direito de seguir os princípios de sua fé (cf. http://twixar.me/5Rxn). Em 2016, lança-se \#NãoEmNomeDeDeus, como forma de repúdio ao uso do nome de Deus repetido por deputados e deputadas dos mais diversos partidos. A ideia é mobilizar pessoas de diferentes confissões religiosas para reafirmar a necessidade de que o Estado permaneça laico, de fato e de direito, de modo que credos religiosos (sejam eles quais forem) não sejam a razão pela qual se vota neste ou naquele político (FÓRUM ECUMÊNICO BRASIL, cf. http://twixar.me/kBxn). Tanto que, "o nome da campanha defende que todo candidato tem o dever de representar a sociedade como um todo e não apenas grupo religioso ao qual ele pertence" (CONIC, cf. http://twixar.me/kBxn). 
Dessa forma, ficou bastante tangível que as ativistas cristãs, ao contrário do que muitos acreditam, utilizam da sua fé como vetor de ação, de mudança, de libertação. Desenvolveram, ao longo desses, anos várias associações e demandam reconhecimento como sujeitos de suas próprias lutas e como cidadãs repletas de pautas para reivindicar. Utilizam da internet para divulgar suas ideias e aproximar os/as envolvidos/ as. Seu contato on-line é criativo, pois não disponibilizam apenas de recursos textuais, como petições, cartas ou relatórios. As plataformas criam diversas peças multissensoriais. Ocorre uma ação integrada e criativa com o intuito de sensibilizar mais pessoas com seu discurso.

Dentro das associações, e para além delas, as cristãs reivindicam melhores postos dentro das igrejas e o fim da violência contra as muIheres (violência clerical, violência doméstica, entre outras). O sujeito discursivo mulher cristã ocupa as organizações e associações, e passa, dessa forma, a representar o conjunto das mulheres cristãs. Sua fala é limitada por esse espaço que variam desde rede mais formais e de prestígio nacional como coletivos e grupos pequenos com atuação local. São locais de fala que estão inseridos e conectados ao cenário mais amplo da mobilização da sociedade civil, onde se verifica uma intensificação das pautas voltadas para questões identitárias.

O discurso político das feministas cristãs é dinâmico e frágil, porque está o tempo todo em contraposição com outros discursos produzidos em outros níveis da sociedade. O sujeito mulher cristã ilude-se achando que é dono do seu dizer, achando que é o criador da sua narrativa, quando na verdade, seu dizer remete à formação discursiva que o domina/determina. Todo o discurso nesses espaços institucionais é estabelecido em confronto e numa relação de oposição a dois polos principais: 1) a sociedade secular/ alguns movimentos feministas; e 2) a religião cristã oficial. Sendo esses enfretamentos pouco fixos, inclusive quando se critica certas atitudes e ações de grupos seculares em relação a preconceitos sobre a religião, e apoia-se, muitas vezes, junto à luta maior das feministas para a emancipação das mulheres. Dessa forma, os confrontos se misturam e as fronteiras são borradas. Os enfretamentos acontecem todas as horas e em todas as frentes. O confronto em cada nível é embasado em articulações e coalizões discursivas múltiplas. 
Diferentemente do que a lente feminista secular vê como modelo emancipatório, que distancia todo e qualquer tipo de libertação do enquadramento religioso, as cristãs apresentam outro caminho, na verdade uma pluralidade de possibilidades. A fé, para essas ativistas, deve ser levada em conta como uma força propulsora da autonomia, não de desigualdade. A crença movimenta essas mulheres e marcam suas experiências de ação social e política. À vista, as mulheres cristãs são um grupo heterogêneo, enfrentando desafios diversos, com intensidade distintas e em níveis diferentes, afinal, existem interseções de discriminações. Porém, no centro dessas movimentações vetor da sua ação está a religião, que não é por si só patriarcal ou atrasada, mas que desempenha papel crucial na determinação de suas aspirações e na sua capacidade de mudar.

A realidade de ação das feministas cristãs é de uma luta diária e pesada que tenta transpor desafios gigantescos, que extrapolam da micro comunidade religiosa para a macro comunidade brasileira. E nem sempre os movimentos que buscam a reafirmação e mudanças tem condições práticas de realizar essa afirmação. A força e a intensidade empregada por essas mulheres são proporcionais aos desafios que enfrentam. Elas lutam contra as muitas discriminações que se originam sobre elas: da agressão física e verbal ao assédio, ou através de perguntas ilegais sobre a possibilidade de serem feministas, até quando lhe é negada o cargo nas hierarquias da igreja. A lista, infelizmente, está longe de ser exaustiva, e cabe somente a elas trilhar o caminho para sua igualdade, sendo exatamente isso que elas têm feito. Elas estão ativas, são militantes estão comprometidas. Elas conhecem o outro, masculino ou feminino, crente ou ateu. Participam com eles no esforço comum por justiça. Elas encontraram seu lugar e conseguem se expressar. Todavia, continuam lamentando que alguém fale em seu lugar ou em seu nome, afinal, elas são protagonistas de suas vidas.

Esse artigo apresenta apenas as primeiras impressões de um longo trabalho de pesquisa que estou realizando, com o objetivo de revelar a existência de uma crescente rede de iniciativas de mulheres e de organizações religiosas que tematizam as questões de gênero e que buscam inserções, tanto no debate sobre os direitos, quanto nas políticas públicas que têm se voltado para as mulheres. 


\section{REFERÊNCIAS}

ALVES, Rubem. A volta do sagrado: os caminhos da sociologia da religião no Brasil. Religião e Sociedade. Ed. Civilização Brasileira, 1978, p. 109-141.

BASKE, Sybila (Org.). Mulheres desafiam as igrejas cristãs: Década ecumênica de solidariedade das igrejas com a mulher (1988-1998). Petrópolis: Vozes, 2001.

BRAUDE, Ann. A religious feminist - Who can find her? Historiographical challenges from the national organization for women'. The Journal of Religion, 84 (4), 1004, p. 555-572.

BURITY, Joanildo; MACHADO, Maria das Dores C. A Ascensão Política dos Pentecostais no Brasil na Avaliação de Líderes Religiosos. Revista de Ciências Sociais, Rio de Janeiro, v. 57, n. 3, 2014, p. 601-631.

CHAMBERLAIN, Prudence. The Feminist Fourth Wave: Affective Temporality. Palgrave Macmillan, 2017.

FLICK, Uwe. Designing Qualitative Research, Londres: SAGE Publications Ltd., 2007.

GEBARA, Ivone. Pluralismo religioso: uma perspectiva feminista. In: TOMITA, Luisa; VIGIL, José M.; BARROS, Marcelo (Orgs.). Teologia latino-americana pluralista da libertação. São Paulo: Asett/Paulinas, 2006.

GILL, Rosalind. Análise do discurso. In: BAUER, Martin W.; GASKELL, George (Orgs). Pesquisa qualitativa com texto, imagem e som: um manual prático. Petrópolis: Vozes, 2008, p. 244-270.

YAZBECK-HADDAD, Yvonne. The Dynamics of Islamic Identity in North America. In: YAZBECK-HADDAD, Yvonne; ESPOSITO, Juan (Eds.). Muslims on the Americanization. Nova York: Oxford University Press, 1998, p. 19-46.

JURKEWICZ, Regina Soares. Gênero, poder e religião - ONG em São Paulo: um estudo de caso. Dissertação de Mestrado. Programa de Pós-Graduação em Ciências da Religião. Universidade Metodista de São Paulo, São Bernardo do Campo, 1997.

JURKEWICZ, Regina Soares. Violência Clerical: Abuso sexual de mulheres por padres no Brasil. Tese de Doutorado. Programa de Estudos Pós-Graduados em Ciências da Religião. Pontifícia Universidade Católica de São Paulo, São Paulo, 2006.

MAC MILLAN, Katie e KOENING, Thomas. The wow factor: preconceptions and expectations for data analysis software in qualitative research. Social Sciences Computer Review, v.22, n.2, maio, 2004, p. 179-186.

MATOS, Terezinha; CUNHA, Lucia. DA CONSTITUIÇÃO DE UM CAMPO: GÊNERO, FEMINISMO E RELIGIÃO. Seminário Internacional Fazendo Gênero 10 (Anais Eletrônicos), Florianópolis, 2013.

OLIVEIRA, Pedro Ribeiro. Estudos da Religião no Brasil: um dilema entre academia e instituições religiosas. In: SOUZA, Beatriz M.; GOUVEIA, Eliana H.; JARDILINO, José R. 
(Orgs.). Sociologia da Religião no Brasil: revisitando metodologias, classificações e técnicas de pesquisa. São Paulo: PUC/UMESP, 1998, p. 13-24.

PANASIEWICZ, Roberlei. Fundamentalismo Religioso: história e presença no cristianismo. Anais do X Simpósio da Associação Brasileira de História das Religiões: "Migrações e Imigrações das Religiões". Assis: ABHR, 2008.

PIERUCCI, Antônio Flavio. Reencantamento e Dessecularização. Novos Estudos CEBRAP, n. 49, 1997, p. 99-117.

ROESE, Anete. O modo de fazer religião das mulheres que fundam suas próprias igrejas: feminismo descolonial e feminismo comunitário. Mandrágora, v.24. n. 2, 2018, p. 161-200. FERREIRA, Letícia. DOSSIÊ: Feminismo Descolonial e Religião: debates e aproximações do campo religioso. Mandrágora, v.24. n. 2, 2018, p. 93-95.

SOUZA, Sandra Duarte de. A relação entre religião e gênero como um desafio para a sociologia da religião. Caminhos, volume 6, n. 1, pp. 13-32, 2008.

TOLEDO-FRANCISCO, Crislaine. Passagens híbridas: relações de gênero e pentecostalismo. Dissertação de Mestrado. Faculdade de Filosofia, Letras e Ciências Humanas da Universidade de São Paulo, São Paulo, 2002.

VIEIRA, Maria. “NÃO NOS LIBERTE, NÓS CUIDAMOS DISSO”: AS MUÇULMANAS E A CONSTRUÇÃO DOS SEUS DIREITOS NO CONTEXTO EUROPEU. Dissertação de Mestrado. Programa de Pós-Graduação em Ciência Política. Universidade Federal de Pernambuco, Recife, 2018.

VILHENA, Valéria. Uma igreja sem voz. Fonte Editorial, São Paulo, 2011.

WOLFF, Elias. A Hermenêutica Ecumênica da Fé Cristã: Uma Contribuição ao diálogo entre Católicos e Luteranos no Contexto dos 500 anos da Reforma de Lutero. Perspectiva Teológica, v. 49, n. 1, 2017, p. 101-125.

WOODHEAD, Linda. Feminism and the Sociology of Religion: From Gender-Blindness to Gendered Difference. FENN, Richard K. (Ed.). The Blackwell Companion to Sociology of Religion. Oxford and Malden: Blackwell, 2001, p. 67-84.

Submetido em: 19-8-2019

Aceito em: 17-10-2019 